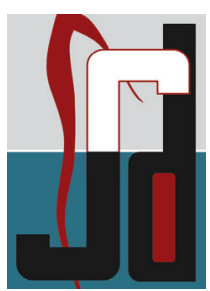

SHORT COMMUNICATION

\title{
Role of Yoga in Salutogenesis
}

Geena Mary. $\mathrm{G}^{1}$

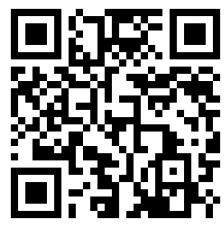

\begin{abstract}
The term yoga originates from Sanskrit which denotes "to join" or "to unite"[1], and term salutogenesis originates from latin and greek meaning health and origin respectively [7]. Though the origin of both differs, their concept towards health application is the same. Early vedic literature on yoga reveals it was a way of meditation practiced by ancient Indian saints to control body and mind activities.[1] Aaron Antonovsky a medical sociologist belonging to late 20 th century, felt that human well being is related to stress free lifestyle and adapting to life as it comes and he proposed model namely salutogenic model which deals with abovementioned factors[7]. Stress and lifestyle modifications which offflate are the predisposing factors for deadly non communicable diseases have to maneuvered to save the future generation. Hence, management for human well being could be handled by yoga through salutogenic approach since both are considered to be the medical model rather than surgical model of treating disease, wherein the disease is managed taking into considerations of health status, physical and mental condition of a person to achieve well being.
\end{abstract}

Key words: yoga, health promoting , lifestyle modifications, salutogenesis, positive health

\section{Introduction}

In the era of digital technology, incidence of life style disorders takes the top order of all diseases affecting human well being owing to heap of options for physical comfort. This has resulted in shift from acute life threatening infectious diseases to chronic non life threatening conditions, which is attributable to stressful and busy hectic schedules, work culture leading to irritability, obesity, loss of libido and decreased life expectancy. Not being able to balance the family and work place also leads to negative effect on cognitive, behavioral, autonomic and somatic functions in a human being. ${ }^{[2]}$ Hence this shift had to be addressed with respect to a different concept, namely trying to understand the source of it, rather providing pills, in short the mystery behind the pathogenic illness should be sorted out and treatment to be planned based on salutogenic approach.

According to Antonovsky, who proposed Salutogenesis, human beings are categorized into healthy status or sick, but we see people as either non patients whom presumed to be healthy and patients on whom some sort of diagnosis in pinned up. Based on salutogenic approach, every human beings should be assessed by objective signs and subjective symptoms and that the sufferer is a normal person doing routine activities could not be labeled as illness alone. Thus the salutogenic approach does not treat the etiology, but focuses the concentration on the salutary factors that helps to cope up as successfully as possible throughout the rest of the life. Hence it could be understood that salutary factors strengthened ones belief and provides self confidence. ${ }^{[4]}$ Thus the human beings ability to assess and understand the situation and the capacity to move forward in health promoting direction are termed as comprehensibility, meaningfulness and manageability which are the three components of salutogenesis. ${ }^{[5]}$

Salutogenesis deals with happiness, enthusiasm, hope, fun, joy, laughter and excitement, whereas yoga an ancient art creates harmony among three components such as body, mind and spirit which in turn supports wellness. If one component doesn't function properly it would lead to illness rather than disease. If a human being could adapt and practice both they tend to live longer with positive health behavior and mental strength thereby leading a good quality of life which Antonovsky termed as sense of coherence, as the saying goes that confidence is half the cure. ${ }^{[9]}$

Application of yoga in salutogenesis in the field of medicine would lead to shift in paradigm of treatment plan for human well being. Hence researches are being under way to adapt as method of decision making and 
treatment planning. The regular practice of yoga such as yogic diet, Asanas, Pranayamas, Mudras, Kriyas reduces physical, mental and emotional stress and insists on right thought, action ,reaction and attitude. ${ }^{[10]}$ The objectives of yoga are focused towards the preserving and conserving physical, mental, social, spiritual health and self realization, thereby facilitating an individual to build in growth in all dimensions of body and soul. ${ }^{[3]}$ These objectives would satisfy any human being with positive lifestyle and peaceful state of mind. ${ }^{[1]}$

Yogic asanas makes the body physically healthy ,makes the mind focused and brings stress under control thereby striking balance between body, mind and soul which enables cordial relationship with family, friends and in work place hence the quality of life too, in other words is indirectly related to salutogensis. At present this concept is been violated by use of smart phones, with credit going to whatsapp and facebook. The relationship towards near or dear ones are replaced with farthest ones through social network.

As per yogic asanas, a person would be able to achieve deep relaxation, which is a salutogenic model that make a person stress free among stressful life underway. Continued regular practice of yoga increases flexibility, strengthens the joints, decreases pulse and respiratory rate, controls triglycerides ,blood pressure and improves physical fitness thereby enhancing both physical and physiological benefits for a human being . In addition to this maintaining a balanced food would aid in good physique. Also studies have shown drastic improvement in sensory-motor performance, handseyes coordination with a relaxed mind.$^{[2]}$ Combination of abovementioned factors in any medical personnel be it physician, surgeon, physiotherapist, occupational therapist etc would be able to achieve job satisfaction in extending their services to patient.

Coming to mental health, any medical personnel undergoing regular yogic principles, would have clarity of thinking, self confidence, positive thoughts, cognitive function, memory power thus a perfect balance in nervous system. Yoga also decreases anxiety, aggression, emotion and depression. Hence they could provide the same to their patients which is the accessory but a vital aid for well being, which is again explained in salutogenic model.
Besides physical and mental health, spiritual health invokes nonviolence and tolerance, that makes any human being forgive and forget, a divine combination, and the most needed concept of the era.

Besides abovementioned factors the main component for healthy living is diet which as per yoga is yogic diet. Yogic diet influences the mind and changes the personality. It is classified into three: 1 . Tamasic food which is a stale or less spoiled food commonly includes alcohol, tobacco, onions, garlic and fermented food such as vinegar which are considered to be impure and filthy and is not fit for consumption. Consuming tamasic food makes a person sedentary leading to obesity. 2. Rajasic Food considered to be the food of Rajas is of hot natured, spicy sour pungent, dry and excessively salty such as beverages, tobacco, green chilies and pepper which functions to stimulate the body and activates the nervous system thereby providing speed, sensual pleasure and physical activity making a person strive to fulfill their uncontrolled passions and desires hence makes the lives pain, grief and disease. 3. Satvic food, the most suitable food for yogi's comprises of natural and fresh cereals, fruits, vegetables, dairy products , nuts and honey which are considered to provide precise balance of nourishment, purifies the mind and enables to function it to a maximum capacity also increases life, strength, inner cheerfulness and happiness, in short a state of quite energy.

Owing to hectic schedule and attractive advertisements of canned foods, even a satvic consumer affords to become a tamasic one. Practicing yogic diet with proper attitude of mind makes a person gain mental control as explained by Antonovsky in salutogenic approach.

In addition to diet, Therapeutic fasting or fasting for health which is complete self denial of all kinds of food except water and air, could be practiced that aids in rejuvenating the entire body by eliminating toxic waste matters of the body thereby paving way for regeneration of diseased tissues, hence considered to be beneficial as it is the natural way of cleansing and regeneration of body and mind. Therefore fasting gives an individual a better control of his appetite, more knowledge of and confidence in ones physical and mental energies and powers. ${ }^{[9]}$

Of all Yogic techniques, Pranayama is an important one to enhance overall performance which is an art and 
science of breathing, if performed with care would eradicate all diseases ,moreover it could be integrated with day today activities, without special equipment ,with less space constraint and not too taxing, This forms the basis for human existence, which in other words termed as respiration. When the breathing is steady and undisturbed, mind also remains the same and vice versa. Yogis attain steadiness in mind by regular practice of pranayama. Hence practicing Yoga gives positive energy, positive vibrations around us which uplifts welfare of mankind. Such a positive lifestyle would yield better tolerance. ${ }^{[9]}$

\section{Conclusion:}

"Health and happiness are your birthright, claim them and develop them to your maximum potential" says Swamiji Gitananda Giri Guru Maharaj. Hence the antiquity of Yoga in combination with modern medicine would improve quality of life of human beings throughout the world. ${ }^{[8]}$ Also the evidence on salutogenic research demonstrates that SOC has an impact on health behaviour, the stronger the SOC the healthier behaviour which speaks in favour of Antonovsky's concept of a healthy orientation ${ }^{[7]}$. A healthy daily routine lays the foundation of a healthy life style.Thus yoga in association with salutogensis provides a platform for being a great personality with values and walk down with a stressful life within us and also around us.

\section{References:}

1. Yadav SK,Ashwani K,Vikas K, Anil K, Importance of yoga in daily life,DOI:10.13140/RG.2.1.4538.3842.

2. Dighore M, J. V. Gadkari. Reducing Anxiety: Effect of Yogic Exercises and Meditation in the Improvement of Anxiety Score, Visual Reaction Time and Finger Dexterity Score. International Journal of Recent Trends in Science And Technology,Vol7( 1); 2013:52-5.

3. Bhardwaj S, Importance, utility \& value of yoga in our life, Asian Journal of Multidimensional Research Vol.1 (4);2012 :204-10.

4. Antonovsky A, Salutogenesis,Studying health vs Studying disease, Lecture at the Congress for Clinical Psychology and Psychotherapy, Berlin, 19 February 1990,

5. Lindstrom B, Eriksson M, Salutogenesis,J Epidemiol Community Health 2005;59:440-2.

6. Lindström B. Eriksson M. The Hitchhiker's Guide to Salutogenesis, Folkhälsan Health Promotion Research Report 2010:2

7. Aaron Antonovsky, The salutogenic model as a theory to guide health promotion, Health promotion international, vol $11 ;(1): 11-8$.

8. Yogacharya Dr Ananda Balayogi Bhavanani, Understanding The Science Of Yoga www.icyer.com

9. Yadav A, Tater SJ ,Medical applications of yoga.10-70

10. Yogacharya Dr Ananda Balayogi Bhavanani, The lotus, 'Moving from Distress to De-stress through Yoga' 24 - 26 September 2010 Brisbane, Australia.

\section{Address of Correspondence}

Dr. Geena Mary.G

Department of Conservative Dentistry and Endodontics Indira Gandhi Institute of Dental Sciences,

Shri Balaji Vidhyapeeth, Pudhucherry - 607402.

Contact number: 9003337902

Email id: geenam@igids.ac.in

\section{Authors:}

${ }^{1}$ Tutor, Department of Conservative Dentistry and Endodontics, Indira Gandhi Institute of Dental Sciences, Pondicherry

\section{How to cite this article :}

Geena Mary.G. Role of Yoga in Salutogenesis. Journal of Scientific Dentistry, 2016;6(2):73-75

Source of Support : Nil, Conflicts of Interest : None declared 